\title{
Analyzing Network Model for Organic Vegetable Distribution: A Case Study of Zhengzhou City
}

\author{
Aiguo Wang $\left(D,{ }^{1}\right.$ Yazhe Wang, ${ }^{2}$ and Qinghai Chen ${ }^{3}$ \\ ${ }^{1}$ College of Land and Tourism, Luoyang Normal University, Luoyang 471934, China \\ ${ }^{2}$ IUT D'orsay Université Paris-Saclay, Orsay 91400, France \\ ${ }^{3}$ Hangzhou Gisway Information Technology Co. Ltd., Hangzhou 311121, China \\ Correspondence should be addressed to Aiguo Wang; wangaiguo@lynu.edu.cn
}

Received 25 April 2021; Revised 25 May 2021; Accepted 31 May 2021; Published 9 June 2021

Academic Editor: Fazlullah Khan

Copyright ( $\odot 2021$ Aiguo Wang et al. This is an open access article distributed under the Creative Commons Attribution License, which permits unrestricted use, distribution, and reproduction in any medium, provided the original work is properly cited.

Due to rapid population growth and increasing demand for high-quality and fresh agricultural products, it is essential to develop advanced transportation networks and distribution centers for perishable vegetables, particularly in urban areas. In this paper, a distribution center model is designed to speed up urban vegetable distribution and reduce transportation and economic costs. This paper develops an algorithm to solve the nonlinear problem and provides numerical analysis to illustrate the proposed solution. It discusses the effects of various system parameters on the decisions and total transportation cost. An improved model of the location selection for the organic vegetable distribution center and sorting center is calculated. The optimum locations of urban organic vegetables distribution center and sorting center are achieved. A real case of an agricultural product supply chain in Zhengzhou City is used to verify the model. The results of this study can serve as a reference for business administrators and managers.

\section{Introduction}

In any society, fulfilling the needs of the public, mainly food, is one of the most significant and perhaps the most primary elements of urban services. Besides, providing welfare and ease for people requires proper deployment, optimal distribution, the perfectness of applications and usages, and diversity of supplied products in markets and shopping centers [1]. The proper deployment of distribution centers significantly impacts reducing intracity trips and traffic jams and cost savings. It is impossible to properly deploy distribution centers without considering the geographical factors of population, location, space, and other factors such as transportation infrastructures, land, fair access, adaptability, population density, capability, capacity, and environment $[2,3]$.

With the continuous improvement of China's domestic living standards in recent years, the people's requirements for fresh vegetable food are getting higher. In 2008, the total production volume of vegetables reached seven hundred million tons in China. Compared with the production volume in 2007, it had increased by 2685 tons. However, the distribution of fresh food products and organic vegetables is challenging and risky due to such products' perishable nature [4]. Having a robust distribution system to dispense vegetables decreases food deterioration and increases the customer service satisfaction level. In the present study, a distribution network is investigated to optimize the organic vegetable distribution operations and simultaneously reduce the economic and environmental costs. In addition, it is attempted to minimize the response time in the distribution network [5].

The contributions of this paper are as follows. First, this study presents a solution approach for solving the vegetables distribution network location selection problem. Second, we conducted a numerical analysis to discuss the effects of the varying parameters and provide the management implications. Third, we applied our method to an agricultural product distribution system in Zhengzhou City in this paper. Results of the present study indicate the high efficiency of the 
proposed model in achieving its objectives and the preference of the augmented approach compared with the traditional one. In the end, the conclusion, as well as some suggestions for future studies, is provided.

The rest of the paper is organized as follows: Section 2 describes related work. Section 3 illustrates the methods for calculating distribution center radius, sorting center, and optimizations. In Section 4, a case study of Zhengzhou City in China is presented. Finally, the conclusion of this work is given in Section 5.

\section{Literature Review}

There are several distinct characteristics of fresh vegetable transportation. These characteristics include perishability of vegetables, seasonality in production, conditioned transportation and storage, vegetable safety issues, and natural conditions that affect the quantity and quality of vegetables. In general, fresh chain logistics builds customer value by merging logistics activities related to perishable products with common business processes. In one relevant study, Hsiao et al. [6] modeled and resolved a cold-chain distribution planning problem for perishable foods by generating a distribution plan that fulfilled customer requirements for various foods and food quality levels at the lowest cost. In another relevant study, Hsiao et al. [7] examined the problem of last-mile delivery of fresh vegetables and fruits by considering multiple practical scenarios. A last-mile routing with the quality concern for cold-chain delivery was explored. The results showed that the fulfillment of various requirements by different customers and quality levels could be guaranteed using the cost of vegetables and fruits. Hsu and Liu [8] proposed a model of facilities for a joint temperature variant distribution system. The optimal application of multitemperature logistics techniques for terminal and vehicle routing operations was solved by minimizing the total delivery cost. Ma et al. [9] proposed the combined order selection and time-dependent vehicle routing problem with a time window in distributing perishable products. This study intended to regulate order delivery, service sequence, and timing to start a delivery task to take full advantage of profit maximization. Likewise, Musolino, Rindone, Polimeni, and Vitetta [10] integrated location and vehicle routing problems for planning an Urban Distribution Center (UDC) based on the restocking demand scenarios. This study aimed to support city logistics planning and evaluate the cost and benefits of the logistics operators.

In summary, from the literature review, it can be concluded that several previous studies have proposed several solutions to solve the network design problem in fresh food and vegetable logistics. The majority of them have focused on minimizing cost as the economic dimension of sustainability. However, only a few previous research works considered the social and environmental dimensions. Moreover, a few previous studies investigated the exact locations and transporting routes among product origins and destinations. Most previous studies presented the results based on the number of locations, travel time, travel distance, and the number of routes.
Designing a proper distribution network for vegetables is vital in decreasing the logistics cost and increasing the customer service level. However, none considered the perishable nature of vegetables while designing the supply network system. Distribution of vegetables is involved in the category of cold chains. The products are safe at low temperatures. Preventing the spoilage of perishable products such as vegetables is, therefore, an important task. Spending more resources in preservative efforts by using improved packaging, more adequate cooling facilities, or faster modes of transportation assists in keeping spoilage to a minimum [11]. However, determining the best location for distribution and sorting centers is a serious problem for the fresh food supply chain. This paper incorporates the freshness-keeping effort decision into determining the best location of the distribution center design model. The model concurrently determines the optimal location, allocation, and freshness-keeping effort decisions to maximize the total profit for a fresh food product.

\section{Formulation of Distribution Center Network}

In this study, we considered the distribution network design for vegetables. The model can also be practical for other agricultural products. The network studied in this paper is a multichannel supply chain with farmers selling their vegetables to farmers' associations. Then, the farmers' associations transport and sell vegetables to the wholesaler. The wholesaler helps consolidate shipments arriving from farmers' associations and deliver them to the distribution center. The distribution center downstream meets the demands of retailers and end customers. Figure 1 represents the complete sketch of vegetable distribution from producers to the consumers. In order to meet the requirement of each end-user, the distribution network should be as such to deliver the products on time and regularly.

3.1. Calculation of Service Radius of Organic Vegetable Distribution Center. Agricultural products differ from manufactured goods in terms of supply and demand. It is essential to deliver the products effectively, predictable, reliable, and customer-friendly in the maximum possible service radius. However, this depends on many factors such as the size of our delivery fleet in an area, waiting time by customers, and the ability to deliver products within a reasonable time $[11,12]$. Agricultural products supply is different because of the very seasonal biological nature. At the same time, their demand is comparatively constant throughout the year. Due to delivery time constraints, a direct distribution center requires that each network has its maximum service radius. Within this distribution center, the serviceability of the network should be guaranteed, and the construction cost of the network itself should be the lowest. Moreover, the location of the network should satisfy many customers as possible [13]. The time to deliver the vegetables to the end-user should be the shortest acceptable time, requiring that the distribution network's distance be minimum. The delivery time between the distribution center and end-user can be computed using the following equation: 


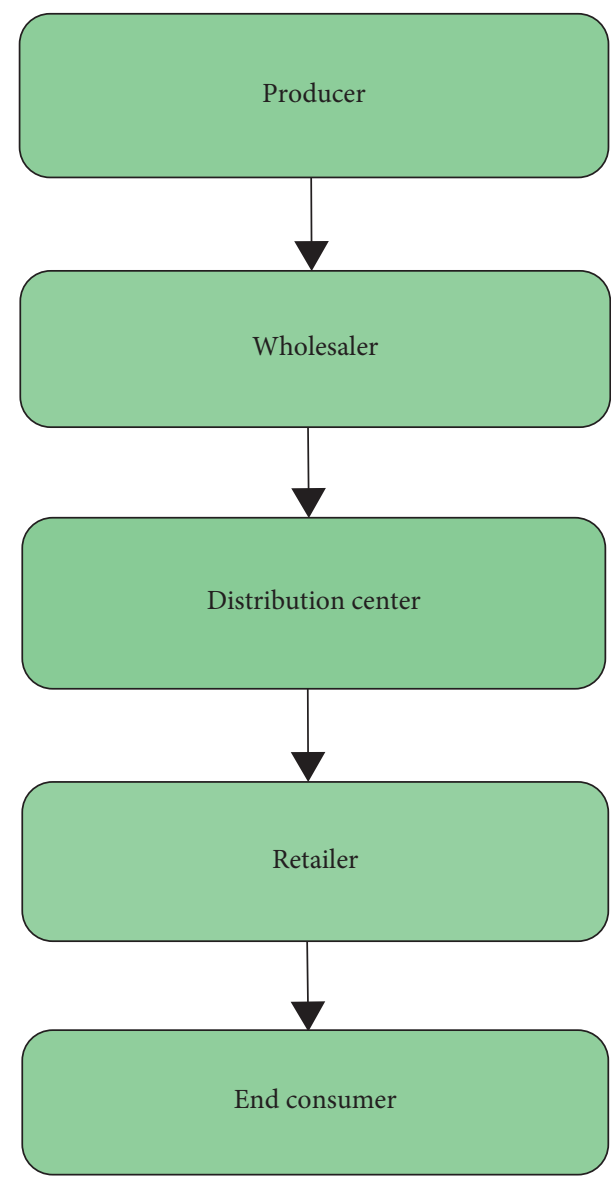

FIGURE 1: Vegetable distribution process.

$$
t_{w-u}=\frac{S_{w-u}}{v_{1}}
$$

where $t_{w-u}$ is the time from the distribution center to the user, $S_{w-u}$ is the distance from the distribution center to the user, and $v_{1}$ is the velocity.

Suppose the maximum time and velocity of the transportation vehicle have been determined. In that case, the maximum network distance can be computed. However, the distance between the network and the user is not always between two direct points in the actual distribution process. It may be through two right angles to reach, as shown in Figure 2.

We suppose the coordinate of the distribution center is $\left(X_{i}, Y_{i}\right)$ and the coordinate of the user is $\left(x_{i}, y_{i}\right)$, then the shortest linear distance from the distribution center to the user can be calculated as

$$
S_{w-u}=\left|X_{i}-x_{i}\right|+\left|Y_{i}-y_{i}\right| \text {. }
$$

The linear distance from the distribution center to the user is obtained using the following equation:

$$
R_{w-u}^{2}=\left(X_{i}-x_{i}\right)^{2}+\left(Y_{i}-y_{i}\right)^{2} \text {. }
$$

To determine the scope of distribution center services, we must satisfy $S_{w-u}=\max$, and then the radius of the distribution center can be computed as

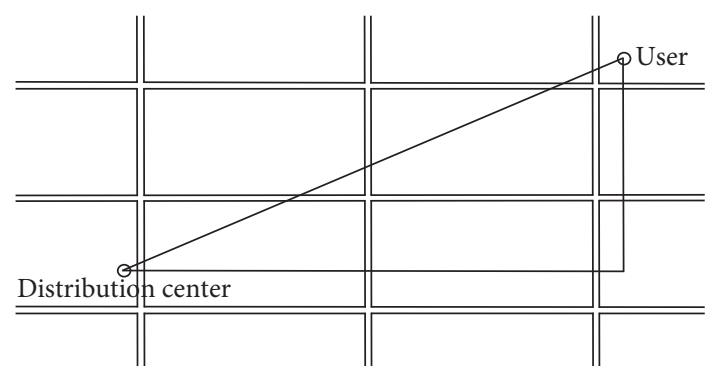

Figure 2: Calculation of the distance from the distribution center to the user.

$$
R_{w-u}=\sqrt{2}\left|X_{i}-x_{i}\right|
$$

After the service radius of the distribution center is calculated, the whole area can be divided into different regions according to the service radius. The area of each circular region can be computed as

$$
S_{Y}=\frac{\pi}{2}\left(t_{w-u} \cdot v_{1}\right)^{2}
$$

However, there may still be many blind spots between the two circular regions, which may cause some customers to have not been delivered properly.

Therefore, it is necessary to optimize it, using a regular inline hexagon instead of a circle for segmentation so that each equilateral hexagon has the same area in the range. There is no blind area in the distribution center, as shown in Figure 3. The regular hexagonal area is calculated using the following equation:

$$
S_{L}=\frac{3}{4} \sqrt{3}\left(t_{w-u} \cdot v_{1}\right)^{2}
$$

In the actual distribution network setting, first, we may segment by the circle. We can segment according to the regular hexagon. Finally, we segment by the actual street of the distribution area.

\subsection{Organic Vegetable Distribution Center Networks Setting.} Specifically, there exists the general requirement for keeping the products as safe as possible during transportation. In addition, products should be delivered within the predefined time window and, at the same time, meet the expected food quality. These factors complicate the design, location, and planning of the fresh products distribution network [14]. In addition, owing to the increased consumer awareness and government regulations on food safety, several issues have continuously been addressed as the most important problems in the foodservice industry. From the above analysis, it can be concluded that the choice and scope of each distribution network service can be determined. However, finding the optimal location for the distribution center is a challenging task. The location of a distribution center is that, first, the network can satisfy many customers as possible; second, own construction cost should be lowest; third, the timeliness of the distribution network must meet the requirements. According to the 


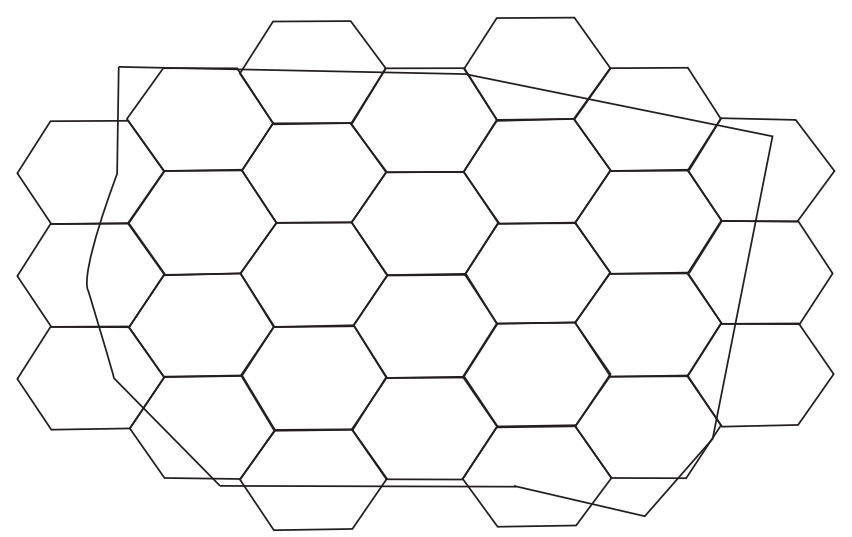

FIgURE 3: Distribution center setting by the regular hexagon.

above principles, we can compute the total cost using the following equation:

$$
\mathrm{TC}=\sum_{i=1}^{m}\left(c \cdot w_{i} \cdot d_{i}+b\right)+f_{1}(x, y)
$$

where TC is the total cost of the distribution center, $c$ is the unit salary per kilogram and per kilometer, $w$ is the number of deliveries, $d$ is the distance from distribution center to the user $\left(d=\left|X_{i}-x_{i}\right|+\left|Y_{i}-y_{i}\right|\right), \mathrm{b}$ is the bottom salary for distribution personnel, $m$ is the total of distribution personnel $\left(m=C_{z} / k\right), C_{z}$ is total distribution volume of the distribution center, $k$ is an average number of delivered customers per delivery person per day, and $f_{1}(x, y)$ is the construction cost. Construction cost is related to location. Because the distribution area is smaller, $f_{1}(x, y)$ can use a quadratic function, that is,

$$
f_{1}(x, y)=a_{0}+a_{1} x+a_{2} y+a_{3} x y+a_{4} x^{2}+a_{5} y^{2} .
$$

Then,

$$
\begin{aligned}
\min (\mathrm{TC})= & \sum_{i=1}^{m}\left(c \cdot w_{i} \cdot\left(\sqrt{\left(x-x_{i}\right)^{2}}+\sqrt{\left(y-y_{i}\right)^{2}}\right)+b\right) \\
& +a_{0}+a_{1} x+a_{2} y+a_{3} x y+a_{4} x^{2}+a_{5} y^{2} .
\end{aligned}
$$

We can obtain

$$
\left\{\begin{array}{c}
x=\frac{\sum_{i=1}^{m}\left(c \cdot w_{i} \cdot\left(x_{i} / \sqrt{\left(x-x_{i}\right)^{2}}\right)\right)-a_{1}-a_{3} y-2 a_{4} x}{\sum_{i=1}^{m}\left(\left(c \cdot w_{i} / \sqrt{\left(x-x_{i}\right)^{2}}\right)\right)}, \\
y=\frac{\sum_{i=1}^{m}\left(c \cdot w_{i} \cdot\left(y_{i} / \sqrt{\left(y-y_{i}\right)^{2}}\right)\right)-a_{2}-a_{3} x-2 a_{5} y}{\sum_{i=1}^{m}\left(\left(c \cdot w_{i} / \sqrt{\left(y-y_{i}\right)^{2}}\right)\right)} .
\end{array}\right.
$$

Equation (8) computes the minimum total cost of product distribution in the distribution center.

3.3. Network Design and Optimization Model of Organic Vegetable Sorting Center. Vegetable sorting centers play an indispensable role in bringing products to the market and consumers [15]. In the supply chain, the sorting center function as the critical point delivers quality products to the users. Put simply, at the sorting center, the products are sorted according to the nature of each product and the demand of each area and are delivered when needed. Although agricultural products can be categorized usually as soft goods or nondurable, they range from being relatively durable to highly perishable. For example, dry foods do not require freezing and can therefore be stored, managed, and delivered at relatively low costs.

In contrast, goods that are perishable such as vegetables require special handling, temperature-controlled environments, and time-sensitive pick-up and delivery $[16,17]$. The choice of sorting center should ensure the lowest cost of vegetable delivery from the vegetable base to the sorting center and from the sorting center to the distribution center. In addition, the construction cost of the sorting center should also be minimized to reduce the overall cost. Figure 4 represents the flow of organic vegetables from the vegetable base to the sorting center and then to the distribution center.

To calculate the construction cost of the sorting center, we suppose that the sorting center's location $m_{i}$ is unit cost, location of vegetable base or distribution center is $\left(x_{i}, y_{i}\right)$, the construction cost of sorting center is $f_{2}(x, y)$, and $\alpha$ is the traffic impact factor. The total cost of the sorting center is as follows:

$$
H=\alpha \sum_{i=i}^{n} m_{i} w_{i}\left(\left|x-x_{i}\right|+\left|y-y_{i}\right|\right)+f_{2}(x, y),
$$

where $f_{2}(x, y)$ can be shown by multisurface function as follows:

$$
f_{2}(x, y)=\sum_{j=1}^{n} a_{j}\left[\left(x-x_{j}\right)^{2}+\left(y-y_{j}\right)^{2}+\delta^{2}\right]^{k} .
$$

Then, we can obtain $H=\min$ as

$$
\begin{aligned}
\min (H)= & \min \left(\alpha \sum_{i=i}^{n} m_{i} w_{i}\left(\left|x-x_{i}\right|+\left|y-y_{i}\right|\right)\right. \\
& \left.+\sum_{j=1}^{m} a_{j}\left[\left(x-x_{j}\right)^{2}+\left(y-y_{j}\right)^{2}+\delta^{2}\right]^{k}\right) .
\end{aligned}
$$

Taking partial derivative, we can get equation (12) as 


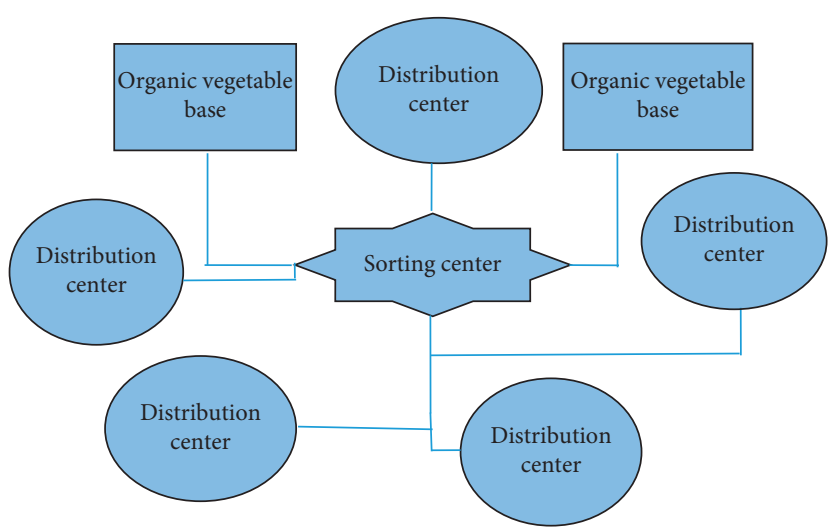

FIGURE 4: Relationship map between sorting center, organic vegetable base, and distribution center.

$$
\operatorname{EE}\left\{\begin{array}{l}
x=\frac{\alpha \sum_{i=i}^{n}\left(m_{i} w_{i} x_{i} /\left|x-x_{i}\right|\right)-2 k \sum_{j=1}^{m} a_{j}\left[\left(x-x_{j}\right)^{2}+\left(y-y_{j}\right)^{2}+\delta^{2}\right]^{k-1}\left(x-x_{j}\right)}{\alpha \sum_{i=i}^{n}\left(m_{i} w_{i} /\left|x-x_{i}\right|\right)}, \\
y=\frac{\alpha \sum_{i=i}^{n}\left(m_{i} w_{i} y_{i} /\left|y-y_{i}\right|\right)+2 k \sum_{j=1}^{m} a_{j}\left[\left(x-x_{j}\right)^{2}+\left(y-y_{j}\right)^{2}+\delta^{2}\right]^{k-1}\left(y-y_{j}\right)}{\alpha \sum_{i=i}^{n} m_{i} w_{i} /\left|y-y_{i}\right|},
\end{array}\right.
$$

\section{A Case Analysis about Zhengzhou City}

Zhengzhou is the largest city of Henan Province in the People's Republic of China. It is one of the national central cities in the Henan province of China. It is the center of the plain areas and serves as the economic, technological, political, and educational center of the Henan. The city is located on the southern bank of the Yellow River. Zhengzhou is the main center of China's national transportation network, with railways and airports linking Zhengzhou to Europe. Moreover, Zhengzhou is a state-list famous historical and culture city. It is one of the most populated cities in China, with a population of $10,120,000$ residents. It is also one of the highly polluted cities worldwide due to its increased population, industries, number of vehicles, and excessive increase in the consumption of fossil energies. Zhengzhou has a GDP of 1.014 trillion (RMB) in the year 2018. The city is one of the main built-up zones of Henan province. Air pollution is among the most important environmental issues challenging the people living in this city. A considerable portion of the air pollution in cities is created by motor vehicles and moving resources. Figure 5 shows the urban planimetric map of Zhengzhou City.

We construct an organic vegetable distribution network in the urban area. Firstly, the number of distribution centers is calculated. Since the distribution center is close to the end-user, the distribution center's distribution to the user is transported by nonmotor vehicles. It is required that the arrival time from the distribution center to the user is not more than one hour. According to road traffic safety law provisions, the maximum operating speed of nonmotorized vehicles is not more than $15 \mathrm{~km} / \mathrm{hr}$.
Considering the situation in urban transportation, it is more appropriate to run at $60 \%$ of the maximum speed. At the same time, due to the requirement of direct distribution to users, nonmotorized vehicles cannot directly reach the customer's house, and they also need to walk for some time. Generally, walking time accounts for $40 \%$ of the total transportation time. In this way, the operating speed from the distribution center to the end customer is computed as

$$
v=15 \times 0.6 \times(1-0.4)=5.4 \mathrm{~km} / \mathrm{hr} .
$$

Then, we can obtain the radius of the distribution center as follows:

$$
R=\frac{\sqrt{2}}{2} \times 1 \times 5.4 \approx 3.8 \mathrm{~km} \text {. }
$$

We can obtain the service area of each distribution center by a hexagon as follows:

$$
S_{L}=\frac{3}{4} \sqrt{3}\left(t_{w-u} \cdot v_{1}\right)^{2} \approx 39 \mathrm{~km}^{2}
$$

Figure 6 is the distribution area divided by a regular hexagon in the urban area. A regular hexagon is about $39 \mathrm{~km}^{2}$.

In the actual distribution, it is impossible to divide according to the regular hexagon. Therefore, we divide the entire region by the streets. Therefore, according to the actual urban streets, the regions divided in Figure 6 are readjusted according to the streets, as shown in Figure 7. The green range line in Figure 7 is the distribution area adjusted by the actual urban streets, which is redivided into seven regions from the original nine regions. 


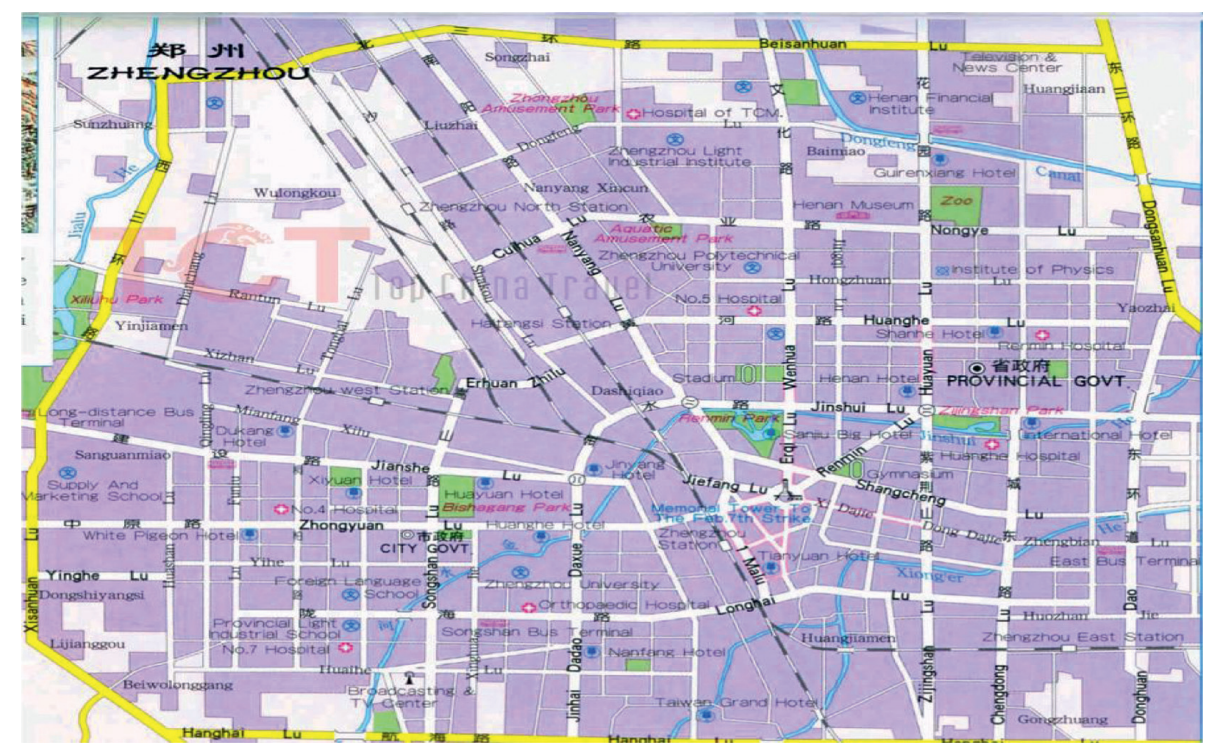

Figure 5: The urban planimetric map of the Zhengzhou City in China.

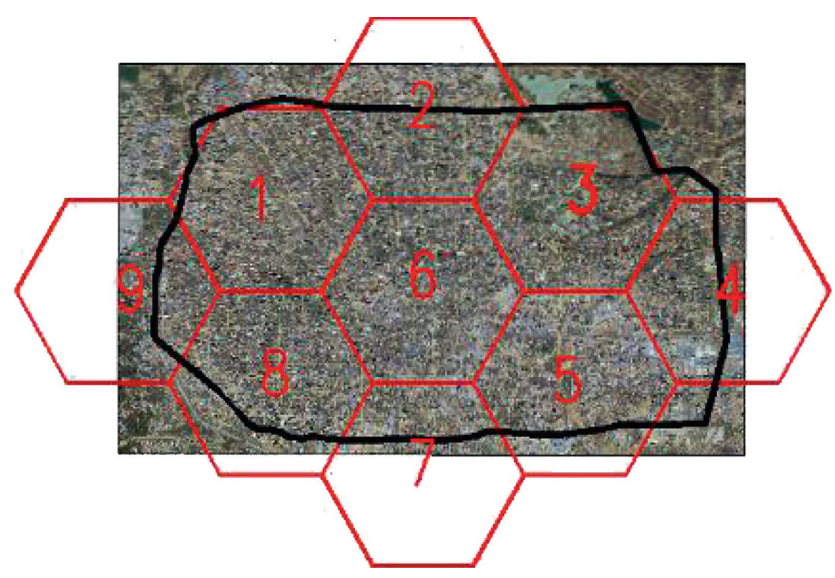

Figure 6: Distribution area by a regular hexagon.

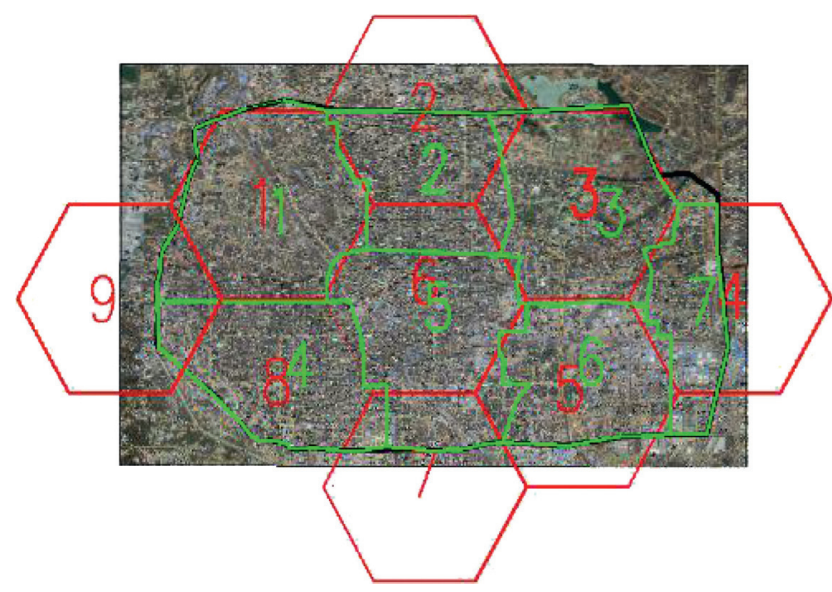

FiguRE 7: Distribution area by actual streets.

The location of distribution centers in seven distribution areas is determined. First, the function of the construction cost of seven areas is obtained. The construction cost of

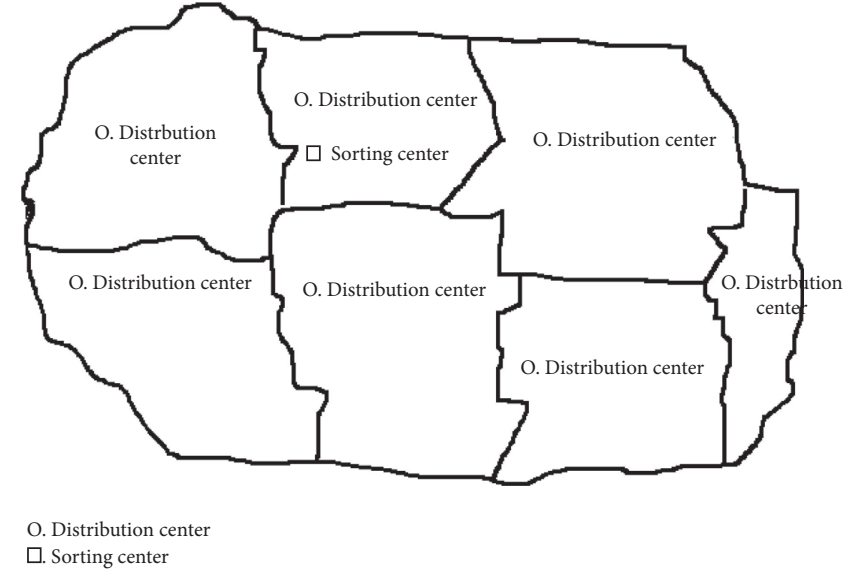

Figure 8: Distribution map of direct distribution center and sorting center after optimized calculation.

seven areas is computed through several points in the collection area. Since the data collected by Google Earth are the longitude and latitude coordinates, the calculation is not convenient, so we obtain rectangular plane coordinates by coordinate projection calculation. The ellipsoid parameter is WGS84 ellipsoid when Gaussian projection is carried out. Figure 8 represents the distribution map of the direct distribution center and sorting center after optimization calculation.

\section{Conclusion}

The rational allocation of organic vegetable distribution networks can bring cost control to enterprises in urban organic vegetable supply, bring profit for enterprises, and make rational use of limited resources. The reasonable layout of the network will play a vital role in the optimal allocation of resources for modern enterprises in the market economy. In this paper, the network layout is optimized theoretically 
using numerical analysis. At the same time, through the example of the actual data of Zhengzhou City, the network layout in mathematical theory has been practiced in practical application. This paper discusses the model of organic vegetable network radius, distribution center, and sorting center. It solves the problem of organic vegetable network layout in urban distribution. The results of this study are a valuable reference for managerial decision-making and administration. Further study must apply the proposed optimized model to estimate the distribution centers in other populated cities.

\section{Data Availability}

The datasets used and/or analyzed during the current study are available from the corresponding author on reasonable request.

\section{Conflicts of Interest}

The authors declare that they have no conflicts of interest.

\section{References}

[1] S. Shashi, R. Cerchione, R. Singh, P. Centobelli, and A. Shabani, "Food cold chain management," The International Journal of Logistics Management, vol. 29, no. 3, pp. 792-821, 2018.

[2] S. Mejjaouli and R. F. Babiceanu, "Cold supply chain logistics: system optimization for real-time rerouting transportation solutions," Computers in Industry, vol. 95, pp. 68-80, 2018.

[3] A. Gallo, R. Accorsi, G. Baruffaldi, and R. Manzini, "Designing sustainable cold chains for long-range food distribution: energy-effective corridors on the Silk Road Belt," Sustainable, vol. 9, 2017

[4] T. Bosona, I. Nordmark, G. Gebresenbet, and D. Ljungberg, "GIS-based analysis of integrated FoodDistribution network in local food supply chain," International Journal of Business \& Management, vol. 8, p. 13, 2013.

[5] B. Bozkaya, S. Yanik, and S. Balcisoy, "A GIS-based optimization framework for competitive multi-facility locationrouting problem," Networks and Spatial Economics, vol. 10, no. 3, pp. 297-320, 2010.

[6] Y.-H. Hsiao, M.-C. Chen, and C.-L. Chin, "Distribution planning for perishable foods in cold chains with quality concerns: formulation and solution procedure," Trends in Food Science \& Technology, vol. 61, pp. 80-93, 2017.

[7] Y.-H. Hsiao, M.-C. Chen, K.-Y. Lu, and C.-L. Chin, "Last-mile distribution planning for fruit-and-vegetable cold chains," The International Journal of Logistics Management, vol. 29, no. 3, pp. 862-886, 2018.

[8] C.-I. Hsu and K.-P. Liu, "A model for facilities planning for multi-temperature joint distribution system," Food Control, vol. 22, no. 12, pp. 1873-1882, 2011.

[9] Z.-J. Ma, Y. Wu, and Y. Dai, "A combined order selection and time-dependent vehicle routing problem with time widows for perishable product delivery," Computers \& Industrial Engineering, vol. 114, pp. 101-113, 2017.

[10] G. Musolino, A. Polimeni, and A. Vitetta, "Freight vehicle routing with reliable link travel times: a method based on network fundamental diagram," Transportation Letters, vol. 10, no. 3, pp. 159-171, 2016.
[11] V. Marianov and D. Serra, "Location problems in the public sector," in Facility Location: Applications and Theory; Springer, Berlin Heidelberg, Germany, 2002.

[12] S. Wang, F. Tao, and Y. Shi, "Optimization of location-routing problem for coldchain logistics considering carbon footprint," International Journal of Environmental Research and Public Health, vol. 15, 2018.

[13] S. Fazayeli, A. Eydi, and I. N. Kamalabadi, "Location-routing problem in multimodal transportation network with time windows and fuzzy demands: presenting a two-part genetic algorithm," Computers \& Industrial Engineering, vol. 119, pp. 233-246, 2018.

[14] B. Kallehauge, J. Larsen, B. G. Oli, and M. M. S. Madsen, "Vehicle routing problem with time windows," in Column Generation; GERAD 25th Anniversary Series, pp. 67-98, Springer, New York, NY, USA, 2005.

[15] A. Hertz and D. De Werra, "The tabu search metaheuristic: how we used it," Annals of Mathematics and Artificial Intelligence, vol. 1, no. 1-4, pp. 111-121, 1990.

[16] M. Jemai, S. Dimassi, B. Ouni, and A. Mtibaa, "A metaheuristic based on the tabu search for hardware-software partitioning," Turkish Journal of Electrical Engineering \& Computer Sciences, vol. 25, pp. 901-912, 2017.

[17] F. Glover and M. Laguna, Tabu Search, Kluwer Academic Publishers, Norwell, MA, USA, 1997. 